Proceedings of the International Conference on Oxide Materials for Electronic Engineering, May 29-June 2, 2017, Lviv

\title{
Refinement of the Modulated Structures of Pb-Free and Pb-Doped Bi-2223 HTSC
}

\author{
O. Shcherban ${ }^{a, b, *}$, L. Akselrud ${ }^{a}$, E. Giannini ${ }^{c}$ And R. GladyshevskiI ${ }^{a}$ \\ ${ }^{a}$ Department of Inorganic Chemistry, Ivan Franko National University of Lviv, \\ Kyryla i Mefodiya Str. 6, UA-79005 Lviv, Ukraine \\ ${ }^{b}$ Scientific Consulting Company "Structure-Properties", Sakharov Str. 33, UA-79026 Lviv, Ukraine \\ ${ }^{c}$ Department of Quantic Matter Physics, University of Geneva, \\ quai Ernest-Ansermet 24, CH-1211 Geneva 4, Switzerland
}

\begin{abstract}
The incommensurate modulated structures of $\mathrm{Pb}$-free and $\mathrm{Pb}$-doped $\mathrm{Bi}-2223$ phases were refined on singlecrystal X-ray diffraction data.
\end{abstract}

DOI: 10.12693/APhysPolA.133.1027

PACS/topics: 61.66.Fn, 74.72.-h

\section{Introduction}

Among the members of the high-temperature superconducting Bi-based family $\mathrm{Bi}_{2} \mathrm{Sr}_{2} \mathrm{Ca}_{n-1} \mathrm{Cu}_{n} \mathrm{O}_{2 n+4+\delta}$ $(n=1,2,3)$, the three-layer compound $\mathrm{Bi}_{2} \mathrm{Sr}_{2} \mathrm{Ca}_{2}$ $\mathrm{Cu}_{3} \mathrm{O}_{10+\delta}(\mathrm{Bi}-2223)$ is the most attracting one, because of its high critical temperature $110 \mathrm{~K}$, better transport properties, and potential industrial applications. However, it is difficult to synthesize the Bi-2223 phase, even at the laboratory scale. Partial substitution of $\mathrm{Pb}$ for $\mathrm{Bi}$ facilitates the synthesis, improves the stability, and enhances the superconducting properties. Due to oxygen off-stoichiometry and differences in the translation periods of the atom layers, the real crystal structures of these compounds are complex and exhibit incommensurate modulations (see [1] and references therein). Commensurate approximants of $\mathrm{Bi}_{2} \mathrm{Sr}_{2} \mathrm{CuO}_{6+\delta}$ and $\mathrm{Bi}_{2} \mathrm{Sr}_{2} \mathrm{CaCu}_{2} \mathrm{O}_{8+\delta}$ (Bi-2201 and $\mathrm{Bi}-2212$, respectively) have been refined on single-crystal diffraction data (e.g. $[2,3])$ and the incommensurate structures have been refined in superspace (e.g. $[4,5]$ ). However, the structure of Bi-2223 had not yet been refined, because of the lack of high-quality single crystals.

\section{Experimental details}

Single crystals were grown by the vaporassisted travelling solvent floating zone method $[6,7]$ from samples having the nominal compositions $\mathrm{Bi}_{2.1} \mathrm{Sr}_{1.9} \mathrm{Ca}_{2} \mathrm{Cu}_{3} \mathrm{O}_{10+\delta}$ and $\mathrm{Bi}_{1.84} \mathrm{~Pb}_{0.32} \mathrm{Sr}_{1.84} \mathrm{Ca}_{1.97} \mathrm{Cu}_{3} \mathrm{O}_{10+\delta} \quad\left(\mathrm{Bi}_{2.16} \mathrm{~Pb}_{0.26} \mathrm{Sr}_{2.08}\right.$ $\mathrm{Ca}_{1.95} \mathrm{Cu}_{2.55} \mathrm{O}_{10+\delta}$ from EDX analysis). Diffraction data were collected on a Stoe IPDS II diffractometer equipped with Mo $K_{\alpha}$ radiation, a graphite monochromator, and an imaging plate. The modulation was found to be incommensurate with $q=0.206(5) a^{*}$ for $\mathrm{Pb}$-free and

*corresponding author; e-mail: sccstros@lviv.farlep.net
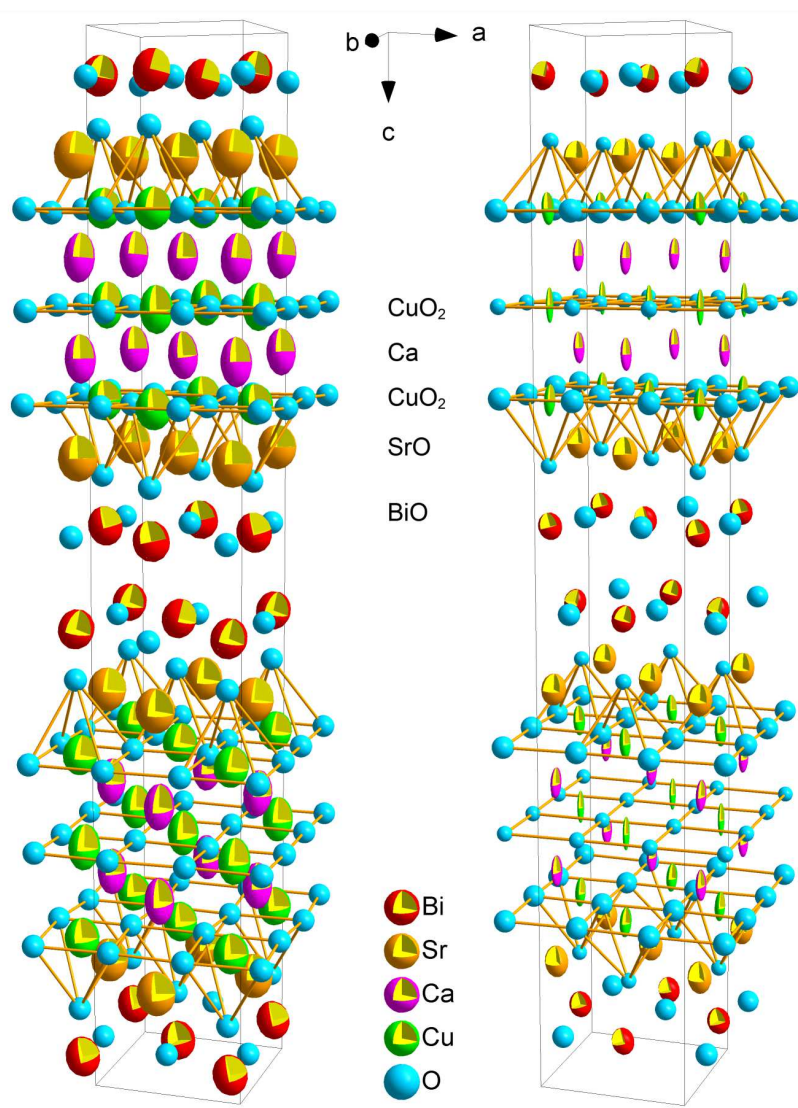

$\mathrm{CuO}_{2}$

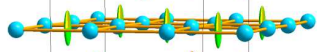

$\begin{array}{lllllllll}0 & 0 & \theta & 0\end{array}$

$\mathrm{CuO}_{2}$

$\mathrm{BiO}$
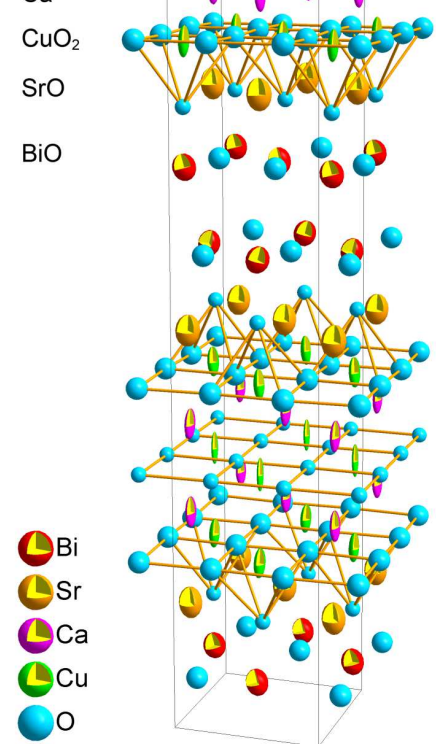

Fig. 1. Crystal structures of $\mathrm{Bi}_{2} \mathrm{Sr}_{2} \mathrm{Ca}_{2} \mathrm{Cu}_{3} \mathrm{O}_{10+\delta}$ (left) and $(\mathrm{Bi}, \mathrm{Pb})_{2} \mathrm{Sr}_{2} \mathrm{Ca}_{2} \mathrm{Cu}_{3} \mathrm{O}_{10+\delta}$ (right) (sequence of atom layers indicated); the atoms are represented by their displacement ellipsoids.

$q=0.20 a^{*}$ for $\mathrm{Pb}$-substituted $\mathrm{Bi}-2223$, i.e. in a rough approximation commensurate with a vector $q=0.2 a^{*}$. The reflections could be indexed in a satisfactory way assuming large primitive orthorhombic cells, which correspond to 5 -fold supercells of the conventional side-face centered orthorhombic cells. The structures 
were refined by the full-matrix least-squares method based on $F$, using the program package WinCSD [8].

\section{Results}

The average structures were refined in the orthorhombic space group $A 2 a a$ with the cell parameters $a=5.4210(7), b=5.4133(6)$ and $c=37.010(7) \AA$ for the $\mathrm{Pb}$-free phase, and $a=5.3952(14), b=5.4130(10)$ and $c=37.042(11) \AA$ for the Pb-doped phase. The Bi site was split into two positions, the two partly occupied sites showing the largest difference in the $x$ coordinates, in agreement with a modulation along $a$. The commensurate approximant superstructures were refined in the orthorhombic space group Pnnn, using a 5-fold supercell (5886 reflections with $I>2 \sigma(I)$ and 302 refined parameters). An additional oxygen site within the $\mathrm{BiO}$ layers was identified.
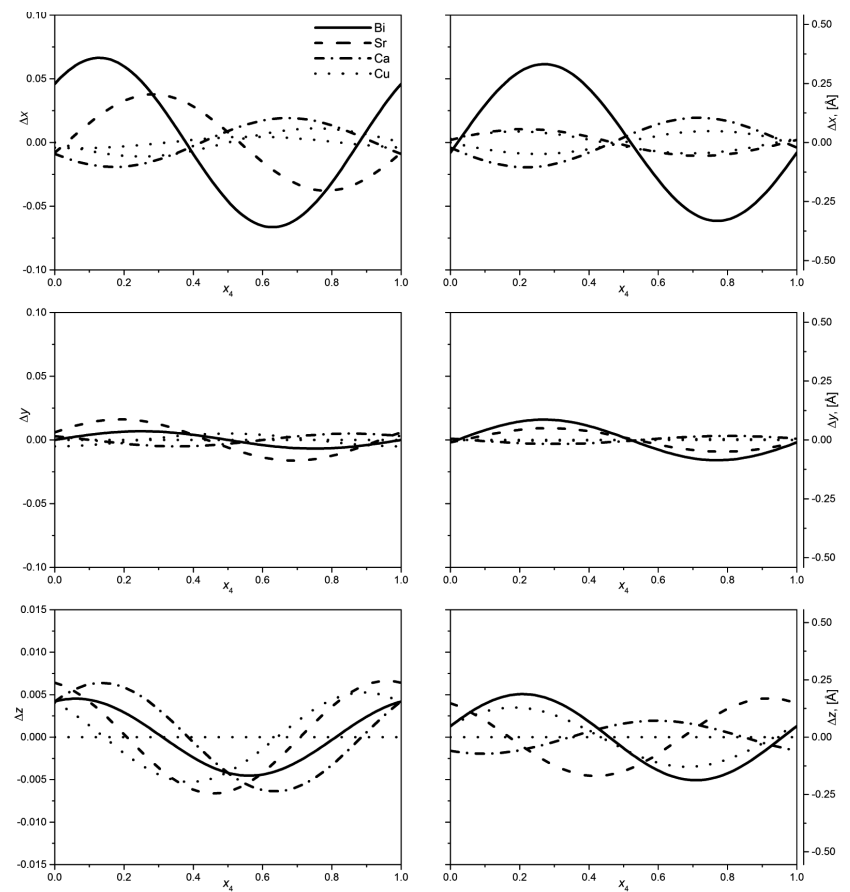

Fig. 2. Displacive modulation of the metal atom sites in $\mathrm{Bi}_{2} \mathrm{Sr}_{2} \mathrm{Ca}_{2} \mathrm{Cu}_{3} \mathrm{O}_{10+\delta}$ (left) and $(\mathrm{Bi}, \mathrm{Pb})_{2} \mathrm{Sr}_{2} \mathrm{Ca}_{2} \mathrm{Cu}_{3} \mathrm{O}_{10+\delta}$ (right).

Refinements of the modulated structures were performed in the $(3+1) \mathrm{D}$-superspace group $A 2 a a(\alpha 00) 000$, considering up to 2nd order satellites corresponding to a modulation vector $\boldsymbol{q}=(0.2,0,0)$. Overall reliability factors of $R=0.1434$ and $0.1383(w R=0.1501$ and 0.1429 ) were achieved for $\mathrm{Bi}_{2} \mathrm{Sr}_{2} \mathrm{Ca}_{2} \mathrm{Cu}_{3} \mathrm{O}_{10+\delta}$ and $(\mathrm{Bi}, \mathrm{Pb})_{2} \mathrm{Sr}_{2} \mathrm{Ca}_{2} \mathrm{Cu}_{3} \mathrm{O}_{10+\delta}$, respectively.

The crystal structure as refined in the average cell is presented in Fig. 1. The fractional atom coordinates, and isotropic and anisotropic displacement parameters are given in Table I and Table II (at the end). The displacive modulation parameters can be obtained from the
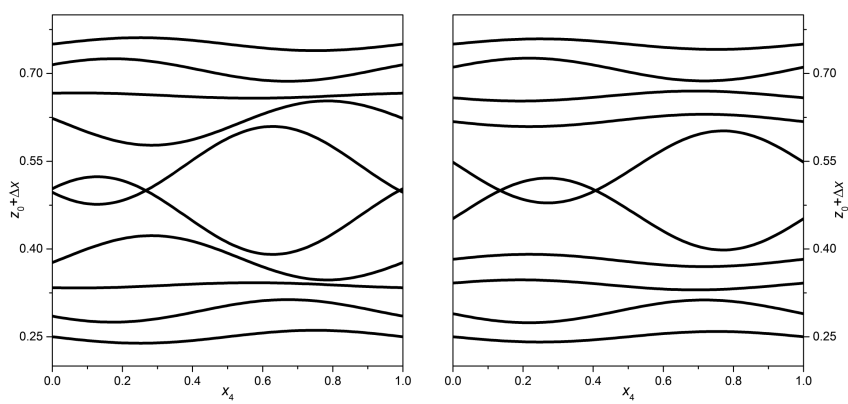

Fig. 3. Displacement of the metal atom sites along $\left[\begin{array}{lll}1 & 0 & 0\end{array}\right]$ in a structure block of $\mathrm{Bi}_{2} \mathrm{Sr}_{2} \mathrm{Ca}_{2} \mathrm{Cu}_{3} \mathrm{O}_{10+\delta}$ (left) and $(\mathrm{Bi}, \mathrm{Pb})_{2} \mathrm{Sr}_{2} \mathrm{Ca}_{2} \mathrm{Cu}_{3} \mathrm{O}_{10+\delta}$ (right).

authors upon request. The average structure was successfully used as starting model for the refinement of the modulated structure, without splitting of the Bi site.

TABLE I

Fractional atomic coordinates in $A 2 a a$ and isotropic or equivalent displacement parameters for $\mathrm{Bi}_{2} \mathrm{Sr}_{2} \mathrm{Ca}_{2} \mathrm{Cu}_{3} \mathrm{O}_{10+\delta}$ and $(\mathrm{Bi}, \mathrm{Pb})_{2} \mathrm{Sr}_{2} \mathrm{Ca}_{2} \mathrm{Cu}_{3} \mathrm{O}_{10+\delta}$ from a refinement in the $(3+1) \mathrm{D}$-superspace group $A 2 a a(\alpha 00) 000$.

\begin{tabular}{|c|c|c|c|c|c|}
\hline \multicolumn{2}{|c|}{ Atom site } & $x$ & $y$ & $z$ & $\bar{U}_{\text {iso/eq }}\left[\AA^{2}\right]$ \\
\hline \multicolumn{6}{|c|}{$\mathrm{Bi}_{2} \mathrm{Sr}_{2} \mathrm{Ca}_{2} \mathrm{Cu}_{3} \mathrm{O}_{10+\delta}$} \\
\hline $\mathrm{Bi}$ & $8 d$ & 0.0 & $0.7290(2)$ & $0.45758(3)$ & $0.0547(3)^{*}$ \\
\hline $\mathrm{Sr}$ & $8 d$ & $0.0128(7)$ & $0.2459(5)$ & $0.38523(8)$ & $0.0632(8)^{*}$ \\
\hline $\mathrm{Ca}$ & $8 d$ & $0.0370(7)$ & $0.2501(6)$ & $0.2951(1)$ & $0.0576(12)^{*}$ \\
\hline $\mathrm{Cu} 1$ & $4 c$ & $0.0316(8)$ & $3 / 4$ & $1 / 4$ & $0.0602(15)^{*}$ \\
\hline $\mathrm{Cu} 2$ & $8 d$ & $0.0111(6)$ & $0.7494(5)$ & $0.33851(8)$ & $0.0544(12)^{*}$ \\
\hline $\mathrm{O} 1$ & $8 d$ & $0.278(3)$ & $0.511(5)$ & $0.1620(4)$ & $0.024(51)$ \\
\hline $\mathrm{O} 2$ & $8 d$ & $0.256(3)$ & $0.005(4)$ & $0.1653(4)$ & $0.024(48)$ \\
\hline O3 & $8 d$ & $0.284(2)$ & $0.010(4)$ & $0.2490(5)$ & $0.024(44)$ \\
\hline $\mathrm{O} 4$ & $8 d$ & $0.027(3)$ & $0.414(5)$ & $0.4542(5)$ & $0.023(75)$ \\
\hline $\mathrm{O} 5$ & $8 d$ & $-0.013(3)$ & $0.259(3)$ & $0.5906(5)$ & $0.022(47)$ \\
\hline \multicolumn{6}{|c|}{$(\mathrm{Bi}, \mathrm{Pb})_{2} \mathrm{Sr}_{2} \mathrm{Ca}_{2} \mathrm{Cu}_{3} \mathrm{O}_{10+\delta}$} \\
\hline $\mathrm{Bi}$ & $8 d$ & 0.0 & $0.7280(1)$ & $0.45762(2)$ & $0.02513(17)^{*}$ \\
\hline $\mathrm{Sr}$ & $8 d$ & $0.0233(4)$ & $0.2479(3)$ & $0.38561(5)$ & $0.0306(5)^{*}$ \\
\hline $\mathrm{Ca}$ & $8 d$ & $0.0320(5)$ & $0.2496(4)$ & $0.29388(7)$ & $0.0209(6)^{*}$ \\
\hline $\mathrm{Cu} 1$ & $4 c$ & $0.0200(7)$ & $3 / 4$ & $1 / 4$ & $0.0187(7)^{*}$ \\
\hline $\mathrm{Cu} 2$ & $8 d$ & $0.0138(5)$ & $0.7501(3)$ & $0.33828(6)$ & $0.0186(5)^{*}$ \\
\hline O1 & $8 d$ & $0.265(3)$ & $0.490(4)$ & $0.1650(3)$ & $0.015(53)$ \\
\hline $\mathrm{O} 2$ & $8 d$ & $0.262(3)$ & $0.008(4)$ & $0.1634(3)$ & $0.015(51)$ \\
\hline O3 & $8 d$ & $0.267(3)$ & $0.004(4)$ & $0.2503(3)$ & $0.014(47)$ \\
\hline $\mathrm{O} 4$ & $8 d$ & $0.100(3)$ & $0.339(4)$ & $0.4564(5)$ & $0.018(85)$ \\
\hline O5 & $8 d$ & $0.019(4)$ & $0.208(4)$ & $0.6008(5)$ & $0.011(92)$ \\
\hline
\end{tabular}

The corrugation of the atom layers and displacements of the atoms within the layers observed in the 3D commensurate approximant, were successfully described by modulation functions in $(3+1) \mathrm{D}$ superspace, using less parameters (Fig. 2). The inclusion of an additional oxy- 
gen atom site inside the $\mathrm{BiO}$ layer, causing displacements of the $\mathrm{Bi}$ atoms within the layer, is the main origin of the modulation in the structure. The size misfit between the rocksalt- and perovskite-type slabs of the structure also leads to corrugation of the atom layers.

The displacements of the atoms along [ $\left[\begin{array}{lll}1 & 0 & 0\end{array}\right]$ induced in the $\mathrm{BiO}$ layer, decay while going towards the central square-planar $\mathrm{CuO}_{2}$ layer (Fig. 3). The displacements of $\mathrm{Bi}$ atoms in neighboring layers are in phase, in contrast to what has previously been observed for members of the series $\mathrm{Bi}-2201$ and $\mathrm{Bi}-2212$, preserving high symmetry without any detectable monoclinic distortion.

\section{Conclusions}

A longitudinal displacement modulation, the magnitude of which increases from the $\mathrm{CuO}_{2}$ to the $\mathrm{BiO}$ layers, was observed. The transverse displacement modulation showed the largest magnitude for the $\mathrm{Cu}$ and $\mathrm{Ca}$ atoms. Similar features were found for $\mathrm{Pb}$-free and $\mathrm{Pb}$-doped samples.

\section{References}

[1] R.E. Gladyshevskii, Ph. Galez, in: Handbook of Superconductivity, Ed. Ch.P. Poole Jr., Academic Press, 1999, p. 267.

[2] M. Onoda, M. Sato, Solid State Commun. 67, 799 (1988).

[3] R.E. Gladyshevskii, R. Flükiger, Acta Crystallogr. B 52, 38 (1996).

[4] A.V. Mironov, V. Petricek, N.R. Khasanova, E.V. Antipov, Acta Crystallogr. B 72, 395 (2016).

[5] V. Petricek, Yan Gao, P. Lee, Ph. Coppens, Phys. Rev. B 42, 387 (1990).

[6] E. Giannini, V. Garnier, R. Gladyshevskii, R. Flükiger, Supercond. Sci. Technol. 17, 220 (2004).

[7] E. Giannini, N. Clayton, N. Musolino, R. Gladyshevskii, R. Flükiger, in: Frontiers in Superconducting Materials, Ed. A.V. Narlikar, Springer-Verlag, 2005, p. 739.

[8] L. Akselrud, Yu. Grin, J. Appl. Crystallogr. 47, 803 (2014).

TABLE II

Anisotropic displacement parameters $\left(\AA^{2}\right)$ for $\mathrm{Bi}_{2} \mathrm{Sr}_{2} \mathrm{Ca}_{2} \mathrm{Cu}_{3} \mathrm{O}_{10+\delta}$ and $(\mathrm{Bi}, \mathrm{Pb})_{2} \mathrm{Sr}_{2} \mathrm{Ca}_{2} \mathrm{Cu}_{3} \mathrm{O}_{10+\delta}$

\begin{tabular}{|c|c|c|c|c|c|c|}
\hline $\begin{array}{l}\text { Atom } \\
\text { site }\end{array}$ & $U_{11}$ & $U_{22}$ & $U_{33}$ & $U_{12}$ & $U_{13}$ & $U_{23}$ \\
\hline \multicolumn{7}{|c|}{$\mathrm{Bi}_{2} \mathrm{Sr}_{2} \mathrm{Ca}_{2} \mathrm{Cu}_{3} \mathrm{O}_{10+\delta}$} \\
\hline $\mathrm{Bi}$ & $0.0486(5)$ & $0.0537(4)$ & $0.0619(8)$ & $0.0014(4)$ & $0.0033(5)$ & $-0.0008(3)$ \\
\hline $\mathrm{Sr}$ & $0.0602(13)$ & $0.0510(11)$ & $0.0785(18)$ & $0.0011(13)$ & $0.0010(10)$ & $0.0023(6)$ \\
\hline $\mathrm{Ca}$ & $0.0318(13)$ & $0.0540(18)$ & $0.087(3)$ & $-0.0003(13)$ & $0.0027(9)$ & $0.0025(10)$ \\
\hline $\mathrm{Cu} 1$ & $0.0357(16)$ & $0.061(3)$ & $0.084(3)$ & 0 & 0 & $0.0018(9)$ \\
\hline $\mathrm{Cu} 2$ & $0.0460(13)$ & $0.0541(14)$ & $0.063(3)$ & $-0.0004(10)$ & $0.0016(9)$ & $0.0001(9)$ \\
\hline \multicolumn{7}{|c|}{$(\mathrm{Bi}, \mathrm{Pb})_{2} \mathrm{Sr}_{2} \mathrm{Ca}_{2} \mathrm{Cu}_{3} \mathrm{O}_{10+\delta}$} \\
\hline $\mathrm{Bi}$ & $0.0225(4)$ & $0.0231(3)$ & $0.0298(3)$ & $-0.0013(3)$ & $0.0020(3)$ & $0.0001(1)$ \\
\hline $\mathrm{Sr}$ & $0.0243(8)$ & $0.0247(8)$ & $0.0428(9)$ & $0.0015(5)$ & $0.0010(5)$ & $-0.0004(4)$ \\
\hline $\mathrm{Ca}$ & $0.0033(9)$ & $0.0179(10)$ & $0.0415(14)$ & $-0.0001(4)$ & $0.0011(5)$ & $-0.0005(5)$ \\
\hline $\mathrm{Cu} 1$ & $0.0015(10)$ & $0.0062(10)$ & $0.0484(14)$ & 0 & 0 & $-0.0003(5)$ \\
\hline $\mathrm{Cu} 2$ & $0.0048(8)$ & $0.0108(8)$ & $0.0401(11)$ & $0.0008(6)$ & $-0.0018(6)$ & $0.0000(4)$ \\
\hline
\end{tabular}

